\title{
Genetic variation in osteopontin gene is associated with susceptibility to sarcoidosis in Slovenian population
}

\author{
A. Maver ${ }^{\mathrm{a}}$, I. Medica ${ }^{\mathrm{a}}$, B. Salobir ${ }^{\mathrm{b}}$, M. Tercelj ${ }^{\mathrm{b}}$ and B. Peterlin ${ }^{\mathrm{a}, *}$ \\ a Institute of Medical Genetics, Department of Obstetrics and Gynecology, University Medical Centre Ljubljana, 3, \\ Šlajmerjeva Street, Ljubljana 1000, Slovenia \\ ${ }^{\mathrm{b}}$ Department of Pulmonary Diseases and Allergy, University Medical Centre, 7, Zaloska Street, Ljubljana 1000, \\ Slovenia
}

\begin{abstract}
Sarcoidosis is a systemic inflammatory disease characterised by appearance of granulomas. Precise etiology has not been elucidated. Osteopontin (Opn) is a Th1 cytokine whose levels have been found increased in granulomas and serum samples from patients with sarcoidosis. We investigated whether genetic variation in Osteopontin gene (OPN) gene contributes to susceptibility to sarcoidosis.

Haplotype-block structure in the OPN gene region was investigated using data from HapMap project. Three representative SNPs have been selected from each block of SNPs in linkage disequilibrium (rs11730582-C/T, rs11728697-C/T and rs4754-C/T). Genotyping was performed using TaqMan SNP Genotyping Assays on a sample of 165 patients and 284 controls. Statistical analyses of association were performed using Chi-Square test and algorithms implemented in the haplo.stats and PHASE packages. Genotyping analysis revealed a significant difference in genotype frequencies at rs 4754 polymorphism in groups of patients and controls under recessive genetic model $(p=0.036, \mathrm{OR}=1.99,95 \% \mathrm{CI}=1.04-3.82)$, $\mathrm{CC}$ homozygotes being significantly over-represented in the patients group. However these results failed to reach significance after correction for multiple testing $(p=0.25)$. The frequencies of predicted haplotypes differed between patient and control groups, frequency of TTT haplotype was found to be significantly decreased in the group of patients with sarcoidosis $(p=0.014$, OR $=0.40,95 \% \mathrm{CI}=0.20-0.79)$. Our results suggest that variation in the OPN gene might be significantly associated with sarcoidosis and that the TTT haplotype in OPN may act as a protective factor in sarcoidosis.
\end{abstract}

Keywords: Sarcoidosis, osteopontin, polymorphism, haplotype, association study

\section{Introduction}

Sarcoidosis is a chronic inflammatory disorder that primarily affects the respiratory system, but also commonly involves several other organ systems. The immune response in sarcoidosis is characterised by overactive T-cell-mediated immune response of Th1 type, resulting in the formation of granulomas in various or-

${ }^{*}$ Corresponding author: Professor Borut Peterlin, MD, PhD, Institute of Medical Genetics, Department of Gynecology and Obstetrics, University Medical Centre Ljubljana, Ljubljana Slovenia. Tel./Fax: +386 1 5401137; E-mail: borut.peterlin@guest.arnes.si. gan systems. Sarcoidosis is hypothesized to be the consequence of environmental factors acting on genetically susceptible individuals, but the exact etiological basis remains unclear. Although the role of various genetic factors has been intensively investigated, the specific genetic background of sarcoidosis remains to be identified [1].

Granulomas of various etiologies, including sarcoidosis, have been shown to contain abundant amounts of osteopontin (Opn) [2,3]. Opn has been found to mediate cell-matrix and cell-cell interactions of immune cells, and to stimulate chemotaxis of macrophages and dendritic cells to sites of active inflammation. Inter- 
estingly, it has also been shown that Opn predominantly stimulates Th1 arm of T-cell mediated immune response [4].

A possible role of Opn in the process of granuloma formation has also been established specifically for sarcoid granulomas. Cells of sarcoid granulomas have been shown to express significant amounts of Opn. Furthermore, Opn levels were found to correlate with granuloma maturity, early granulomas expressing considerably more Opn in comparison to late, fibrotic granulomas. Further functional analyses showed that Opn induced the chemotaxis of T-cells and acted as an adhesion factor for activated $\mathrm{T}$ cells [5].

The OPN gene (SPP1) region has been shown to include several polymorphic sites and significant functional effects of these polymorphisms have been demonstrated. Functional studies performed by Giacopelli et al. have shown that polymorphisms in the SPP1 promoter region may affect its transcriptional activity [6]. Previous haplotype analyses and data available from HapMap database (www.hapmap.org) suggest that SPP1 is located in a region of considerable linkage disequilibrium $[7,8]$. Several authors proposed that few tagging polymorphisms are needed to define genetic variation of the whole SPP1 gene region [7]. To analyse the effect of sequence variation in the OPN gene we selected three single nucleotide polymorphisms (SNPs): rs11730582, rs11728697 and rs4754, located in the promoter region, intron 3 and exon 6 of the OPN gene, respectively, which are roughly spanning the whole OPN gene region.

\section{Methods}

\subsection{Patients}

Subjects diagnosed with sarcoidosis were recruited from an ongoing sarcoidosis registry started in year 2000 at the University Medical Centre Ljubljana, Department of Pulmology and Allergic Diseases. The diagnosis of sarcoidosis was based on the clinical picture, radiographic presentation, bronchoalveolar lavage (BAL) and biopsy specimen from the lung, skin or lymph nodes after other granulomatous diseases were excluded. A hundred and sixty-five patients were included in the study. The patients were followed up from 3 to 10 years after diagnosis confirmation. Regarding the clinical presentation at diagnosis, the data on the study group are summarized in Table 1 (according to standard classification system [1]).
The control groups consisted of 284 age and sex matched healthy blood donors, as shown in Table 1. All patients and control subjects were Slovenian blood donors, not related to each other.

All subjects participated in the study after they had given their full informed consent. The study was approved by the national committee for medical ethics.

\subsection{Selection of SNPS}

Selection of SNPs was based on the analyses of data obtained from the HapMap database. Haplotype structure of the OPN gene region was investigated and haplotype blocks estimated by Haploview algorithms, using data from the HapMap release version 21a, for CEU population (Utah residents with ancestry from northern and western Europe) (Fig. 1).

Figure 1 OPN gene region and its respective LD plot, according to HapMap data for CEU population.

Locations of polymorphisms investigated are represented by three black arrows. Roughly three blocks of linkage disequilibrium are apparent. SNPs were selected to roughly span the whole OPN gene region, each located in one block of LD.

Also, data from previously published reports of haplotype structure in the OPN gene was included in the selection process $[7,8]$.

\subsection{Genotyping}

Genotyping was performed using Taqman predesigned SNP Genotyping Assays from Applied Biosystems (ABI, Foster City, USA), assay numbers C_1840808_10, C_1840811_10 and C_1840817 10 . TaqMan genotyping reactions were performed on ABI 7000 genetic analyzer using $2 \mu \mathrm{l}$ of $(10 \mathrm{ng} / \mu \mathrm{l})$ of genomic DNA following manufacturer's instructions. Florescence was detected on an ABI prism 7000 sequence detection system (ABI, Foster City, USA). Genotypes were scored by analyzing data on both realtime as well as allele discrimination assay platforms using SDS software provided by the ABI.

\subsection{Statistical analyses}

The significance of association for individual SNPs was analyzed using the Chi-Square test $\left(\chi^{2}\right)$. Odds ratios (OR) and their respective $95 \%$ confidence intervals (CI) were also calculated to compare the allelic frequency and genotype distribution in patients and control subjects. Analyses were performed us- 
Table 1

Clinical characteristics of patients and controls included in our study

\begin{tabular}{|c|c|c|c|c|c|}
\hline \multirow[t]{2}{*}{$\begin{array}{l}\text { Mean age (years) } \\
\text { Number of subjects }\end{array}$} & & \multicolumn{2}{|c|}{$\begin{array}{c}\text { Sarcoidosis patients } \\
42( \pm 13.3) \\
165\end{array}$} & \multicolumn{2}{|c|}{$\begin{array}{c}\text { Controls } \\
42.5( \pm 11) \\
284\end{array}$} \\
\hline & & $\mathrm{N}$ & Percentage & $\mathrm{N}$ & Percentage \\
\hline \multirow[t]{2}{*}{ Sex } & Male & 69 & $42 \%$ & 126 & $44 \%$ \\
\hline & Female & 96 & $58 \%$ & 159 & $56 \%$ \\
\hline \multirow[t]{2}{*}{ Pulmonary involvement } & Pulmonary lymph nodes & 143 & & & \\
\hline & Lung interstitium & 131 & & & \\
\hline Löfgren syndrome & & 28 & & & \\
\hline \multirow[t]{8}{*}{ Other organ system involvement } & Skin & 47 & & & \\
\hline & Parenchymal organs. liver, spleen or heart & 26 & & & \\
\hline & Neural & 14 & & & \\
\hline & Arthralgias & 27 & & & \\
\hline & Extrapulmonary node involvement & 16 & & & \\
\hline & Salivary glands involvement & 6 & & & \\
\hline & I & 26 & & & \\
\hline & II & 101 & & & \\
\hline \multirow[t]{2}{*}{ Chest radiographic staging } & III & 26 & & & \\
\hline & IV & 2 & & & \\
\hline
\end{tabular}

rs11730582 rs11728697
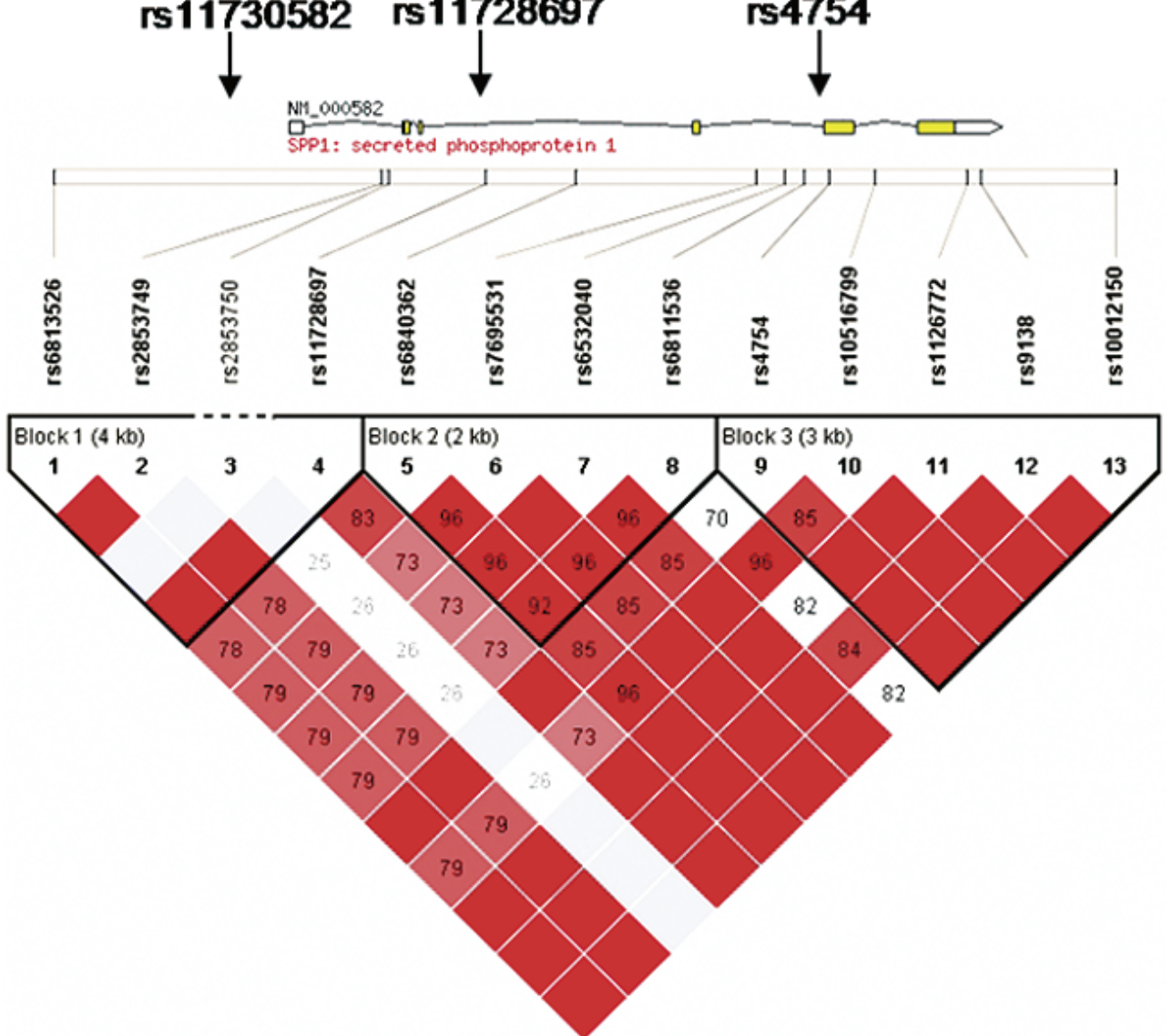

Fig. 1. OPN gene region and its respective LD plot, according to HapMap data for CEU population. Locations of polymorphisms investigated are represented by three black arrows. Roughly three blocks of linkage disequilibrium are apparent. SNPs were selected to roughly span the whole OPN gene region, each located in one block of LD. 
Table 2

Distribution of genotypes in the patient and control groups for rs11730582 SNP

\begin{tabular}{|c|c|c|c|c|c|}
\hline \multicolumn{2}{|c|}{ Allele/Genotype } & \multirow{2}{*}{$\begin{array}{c}\text { Sarcoidosis } \\
\text { n (\%) } \\
154(46.7)\end{array}$} & \multirow{2}{*}{$\begin{array}{l}\text { Controls } \\
\text { n }(\%) \\
264(48.0)\end{array}$} & \multirow{2}{*}{$\begin{array}{l}\text { OR }(95 \% \mathrm{CI}) \\
1.06(0.80-1.39)\end{array}$} & \multirow{2}{*}{$\begin{array}{l}\mathrm{P} \\
0.70\end{array}$} \\
\hline Allele & $\mathrm{C}$ & & & & \\
\hline & $\mathrm{T}$ & $176(53.3)$ & $286(52.0)$ & & \\
\hline & Total & $330(100)$ & $550(100)$ & & \\
\hline & & & & $\mathrm{OR}^{*}(95 \% \mathrm{CI})$ & $\mathrm{p}^{*}$ \\
\hline \multirow[t]{4}{*}{ Genotype } & $\mathrm{CC}$ & $36(21.8)$ & $62(22.6)$ & $1.10(0.72-1.70) /$ & $0.65 /$ \\
\hline & CT & $82(49.7)$ & $140(50.9)$ & $1.04(0.66-1.66) /$ & $0.86 /$ \\
\hline & TT & $47(28.5)$ & $73(26.5)$ & $0.95(0.65-1.40)$ & 0.80 \\
\hline & Total & $165(100.0)$ & $275(100.0)$ & & \\
\hline
\end{tabular}

*P and OR values were calculated under recessive/dominant/codominant models.

ing $\mathrm{R}$ statistical package (http://cran.r-project.org/). A $\chi^{2}$ goodness-of-fit test for deviation from HardyWeinberg equilibrium was also calculated. Tests of statistical power were performed using gap (Genetic analysis package) for $\mathrm{R}$ available from http://cran.rproject.org/web/packages/gap/. Associations were regarded as significant when they reached the $\mathrm{p}$ value of equal to or less than 0.05 .

Frequencies of haplotypes and their associations with sarcoidosis were analysed using haplo.stats statistical package (http://mayoresearch.mayo.edu/mayo/ research/biostat/), which calculates indirectly measured haplotypes, under the assumption that all subjects in the study are unrelated and linkage phase unknown [9]. Statistical power to detect association of risk haplotypes with sarcoidosis was performed using haplo.power method, also provided by haplo.stats.

Additional predictions of haplotype frequencies were calculated using PHASE algorithm [10]. Haploview software (http://www.broad.mit.edu/mpg/haploview/) was used to determine linkage disequilibrium between SNPs investigated in this study and to test for accordance of our observed genotype frequencies with expected Hardy-Weinberg equilibrium [11].

Multiple testing issue for analyses of allele-disease or genotype-disease associations at three selected SNPs has been accounted for by estimating $p$ values adjusted for multiple testing using BenjaminiHochberg method [12]. The effect of multiple testing of haplotype-disease associations has been addressed initially by eliminating haplotypes with frequencies below $5 \%$ in our study group from further statistical analyses. Furthermore, we have corrected the haplotypedisease values by calculation of simulated empirical $p$ values after 20.000 permutation cycles, performed by algorithms provided with haplo.stats package.

In all the tables in the results section, uncorrected $\mathrm{p}$ values are presented.

\section{Results}

\subsection{Power analyses}

Calculation of statistical power revealed that in our group of 165 cases and 284 controls, considering the frequency of sarcoidosis in the general population estimated at $0.2 \%$, we reached a power of $80 \%$ to detect a genotype risk of approximately 2.2 for rs 11730582 (frequency of risk allele 51.0\%), 2.0 for rs 11728697 (frequency of risk allele $38.0 \%$ ) and 2.0 for rs4754 (frequency of risk allele $29.2 \%$ ) under an additive genetic model.

Power calculations for haplotype-disease associations have revealed that in our study we reached power of $80 \%$ to detect OR of 2.2 , considering type I error to be 0.05 and frequency of sarcoidosis in Slovenian population set to 20 affected per 100.000 .

\subsection{Genotyping results}

Results of genotyping analysis at rs11730582 polymorphism did not reveal any statistical significance in genotypes distribution between patients and controls under any of genetic models (Table 2).

Results of genotyping analyses revealed a significant difference in genotype frequencies at rs 4754 polymorphism bezween groups of patients and controls, if the polymorphism considered under recessive genetic model: CC homozygotes vs. CT heterozygotes plus TT homozygotes in patients and controls $(p=0.036$, $\mathrm{OR}=1.99,95 \% \mathrm{CI}=1.04-3.82)$, consequently CC homozygotes significantly over-represented in the patients group (Table 3). However, after multiple testing corrections due to multiple genetic models tested (recessive, dominant and codominant) and three SNPs studied for association with sarcoidosis, distribution of genotypes at this SNP did not reach statistical significance $\left(\mathrm{p}_{\text {corr }}=0.25\right)$. 
Table 3

Distribution of genotypes in the patient and control groups for rs4754 SNP

\begin{tabular}{llccll}
\hline \multicolumn{2}{c}{ Allele/Genotype } & $\begin{array}{c}\text { Sarcoidosis } \\
\mathrm{n}(\%)\end{array}$ & $\begin{array}{c}\text { Controls } \\
\mathrm{n}(\%)\end{array}$ & OR $(95 \% \mathrm{CI})$ & $\mathrm{P}$ \\
\hline Allele & $\mathrm{C}$ & $102(30.9)$ & $162(29.1)$ & $1.09(0.81-1.46)$ & 0.58 \\
& $\mathrm{~T}$ & $228(69.1)$ & $394(70.9)$ & & \\
& Total & $330(100.0)$ & $556(100.0)$ & & \\
& & & & $\mathrm{OR}^{*}(95 \% \mathrm{CI})$ & $\mathrm{p}^{*}$ \\
Genotype & $\mathrm{CC}$ & $21(12.7)$ & $19(6.8)$ & $1.99(1.04-3.82) /$ & $0.04 /$ \\
& $\mathrm{CT}$ & $60(36.4)$ & $124(44.6)$ & $0.91(0.62-1.34) /$ & $0.63 /$ \\
& $\mathrm{TT}$ & $84(50.9)$ & $135(48.6)$ & $0.71(0.48-1.05)$ & 0.09 \\
& Total & $165(100.0)$ & $278(100.0)$ & & \\
\hline
\end{tabular}

${ }^{*} \mathrm{P}$ and $\mathrm{OR}$ values were calculated under recessive/dominant/codominant models.

Table 4

Distribution of genotypes in the patient and control groups for rs11728697 SNP

\begin{tabular}{llccll}
\hline \multicolumn{2}{c}{ Allele/Genotype } & $\begin{array}{c}\text { Sarcoidosis } \\
\mathrm{n}(\%)\end{array}$ & $\begin{array}{c}\text { Controls } \\
\mathrm{n}(\%)\end{array}$ & OR $(95 \% \mathrm{CI})$ & $\mathrm{P}$ \\
\hline Allele & $\mathrm{C}$ & $134(40.6)$ & $216(38.0)$ & $1.11(0.84-1.47)$ & 0.44 \\
& $\mathrm{~T}$ & $196(59.4)$ & $352(62.0)$ & & \\
& Total & $330(100.0)$ & $568(100.0)$ & & \\
& & & & $\mathrm{OR}^{*}(95 \% \mathrm{CI})$ & $\mathrm{p}^{*}$ \\
Genotype & $\mathrm{CC}$ & $31(18.8)$ & $35(12.3)$ & $1.65(0.97-2.79) /$ & $0.06 /$ \\
& $\mathrm{CT}$ & $72(43.6)$ & $146(51.4)$ & $0.95(0.64-1.41) /$ & $0.78 /$ \\
& TT & $62(37.6)$ & $103(36.3)$ & $0.73(0.50-1.08)$ & 0.11 \\
& Total & $165(100.0)$ & $284(100.0)$ & & \\
\hline
\end{tabular}

${ }^{*} \mathrm{P}$ and $\mathrm{OR}$ values were calculated under recessive/dominant/codominant models.

Also, the distribution of genotypes at rs11728697 SNP reached borderline statistical significance when the polymorphism considered under recessive genetic model: CC homozygotes compared to CT heterozygotes plus TT homozygotes in patients and controls $(p=0.06, \mathrm{OR}=1.65,95 \% \mathrm{CI}=0.97-2.79)$, therefore with increased frequency of $\mathrm{CC}$ homozygotes in the patients group (Table 4). Corrected $\mathrm{p}$ values did not reach statistical significance for this $\mathrm{SNP}$ ( $\mathrm{p}_{\text {corr }}=$ $0.25)$.

Genotype frequencies of all three polymorphisms were in accordance with those predicted by the HardyWeinberg equilibrium in control and patients groups $(p<0.05)$.

\subsection{Haplotype analyses at the SPP1 locus}

Haplotype analyses of 3 SNPs in the SPP1 gene region revealed the presence of 5 probable haplotypes with the frequencies above $5 \%$ in our study group. Three most frequent haplotypes accounted for over $80 \%$ of haplotypes observed in our study population. The frequencies of predicted haplotypes in the patient and control groups are represented in Table 5.

A significant difference in haplotype frequencies was observed between the patient and control groups (global simulated $p$ value was estimated at 0.005 , haplo.stats global-stat $=18.27$, df $=6$ ). A statistically significant difference was found when comparing the frequencies of TTT haplotype (rs11730582-T, rs11728697-T, rs4754-T) between the patients with sarcoidosis and controls ( $p=0.01378, \mathrm{OR}=0.40,95 \%$ CI $0.20-0.79$, simulated p-value was 0.0140).

Additional analyses using PHASE revealed that the predicted frequency of the TTT haplotype was 3.3\% in patients with sarcoidosis in comparison with $11.2 \%$ in healthy controls $(\mathrm{OR}=0.27,95 \% \mathrm{CI}=0.14-0.53$, $\left.p<0.0001, \mathrm{p}_{\text {corr }}=0.00013\right)($ Table 5).

Haploview analyses revealed SNPs rs11730582 and rs11728697 to be in complete linkage disequilibrium $\left(D^{\prime}=1.00\right.$, LOD $\left.=99.3\right)$ and also rs11728697 and rs4754 showed strong linkage ( $\mathrm{D}^{\prime}=0.884$, LOD $=26.5)$. SNPs rs11730582 and rs4754 showed little linkage as they are located farthest $(6.3 \mathrm{~kb})$ apart on the OPN gene. Output from analysis of our data in Haploview software is presented in LD plot in Fig. 2. Results of pairwise linkage calculations ( $\mathrm{r}^{2}$ and D' values) for our data are presented in Table 6.

\section{Discussion}

In our study, we have demonstrated an increased frequency of $\mathrm{CC}$ homozygotes at the rs 4754 polymor- 
Table 5

Frequencies and distribution of probable haplotypes in the patient and control groups as predicted by haplo.stats and PHASE algorithms

\begin{tabular}{|c|c|c|c|c|c|c|c|c|c|c|}
\hline \multirow{2}{*}{ Haplotype } & \multirow{2}{*}{ rs11730582 } & \multirow{2}{*}{ rs11728697 } & \multirow{2}{*}{ rs4754 } & \multicolumn{4}{|c|}{ Haplo.stats } & \multicolumn{3}{|c|}{ PHASE } \\
\hline & & & & $\begin{array}{c}\text { Frequency } \\
\text { (patients) }\end{array}$ & $\begin{array}{l}\text { Frequency } \\
\text { (controls) }\end{array}$ & $\mathrm{p}$ & $\begin{array}{l}\text { Simulated } \\
\text { p value }\end{array}$ & $\begin{array}{c}\text { Frequency } \\
\text { (patients) }\end{array}$ & $\begin{array}{l}\text { Frequency } \\
\text { (controls) }\end{array}$ & $\mathrm{p}$ \\
\hline 1 & $\mathrm{C}$ & $\mathrm{T}$ & $\mathrm{C}$ & 0.20 & 0.20 & 0.80 & 0.80 & 0.20 & 0.23 & 0.24 \\
\hline 2 & $\mathrm{C}$ & $\mathrm{T}$ & $\mathrm{T}$ & 0.26 & 0.24 & 0.70 & 0.70 & 0.27 & 0.22 & 0.10 \\
\hline 3 & $\mathrm{~T}$ & $\mathrm{C}$ & $\mathrm{T}$ & 0.39 & 0.33 & 0.13 & 0.13 & 0.39 & 0.34 & 0.16 \\
\hline 4 & $\mathrm{~T}$ & $\mathrm{~T}$ & $\mathrm{C}$ & 0.09 & 0.08 & 1.0 & 1.0 & 0.09 & 0.05 & 0.02 \\
\hline 5 & $\mathrm{~T}$ & $\mathrm{~T}$ & $\mathrm{~T}$ & 0.04 & 0.10 & 0.0138 & 0.0140 & 0.03 & 0.11 & $<0.0001^{\S}$ \\
\hline other & * & $*$ & $*$ & 0.02 & 0.05 & $*$ & & 0.02 & 0.05 & $*$ \\
\hline
\end{tabular}

$\S_{\mathrm{P}}$ value equalled to 0.00013 after corrections for multiple testing.
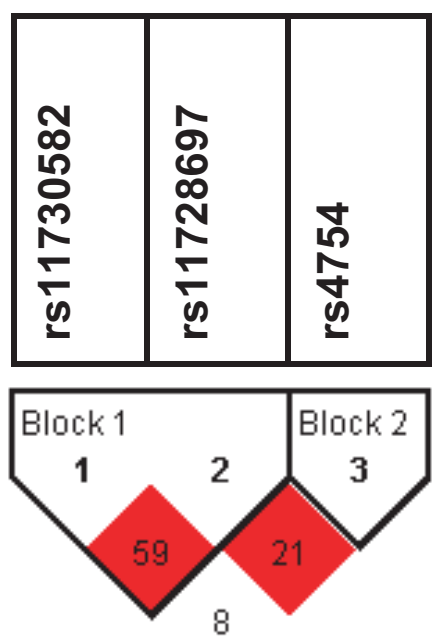

Fig. 2. Haploview output for three SNPs investigated in our study. Higher degree of LD is apparent between SNPs rs11730582 and rs11728697.

phism in the group of patients in comparison with control subjects. Furthermore, we have also demonstrated a decreased frequency of the TTT haplotype of the OPN gene in patients with sarcoidosis in comparison with healthy controls, suggesting a protective role of this haplotype in sarcoidosis.

We selected OPN as a candidate gene for sarcoidosis based on evidence from available functional studies that pointed to its immunological role in sarcoidosis, and also based on the studies reporting an altered OPN expression in granulomas and altered Opn serum levels in sarcoidosis $[5,13]$.

Opn plays a role in a wide spectrum of physiologic and pathologic processes $[2,5,14,15]$. Initially, it was found to mediate the attachment of osteoclasts to bony matrix, thereby mediating bone resorption and normal bone development [15]. Later, its importance in regulating immune response was also recognised [16]. Opn protein is normally present predominantly in mineralised bony tissues but in the presence
Table 6

Pairwise LD among SNPs included in our study (D' and $\mathrm{r}^{2}$ values)

\begin{tabular}{lllcc}
\hline & & \multicolumn{3}{c}{$\mathrm{D}^{\prime}$} \\
\cline { 3 - 5 } & $\mathrm{SNP}$ & $\mathrm{rs11730582}$ & $\mathrm{rs11728697}$ & $\mathrm{rs} 4754$ \\
\hline \multirow{3}{*}{$\mathrm{r}^{2}$} & $\mathrm{rs} 11730582$ & & 1.000 & 0.425 \\
& $\mathrm{rs11728697}$ & 0.595 & & 0.884 \\
& $\mathrm{rs} 4754$ & 0.082 & 0.210 & \\
\hline
\end{tabular}

of inflammation its levels increase in other types of tissue, due to its secretion by macrophages, T-cells and NK cells [17]. Opn's immunoregulatory function is related to its chemotaxic effects on macrophages and T-cells and its effects on expression of Th1 and Th2 cytokines [18]. It is generally believed that Opn acts as a pro-inflammatory cytokine, but anti-inflammatory properties of Opn have been observed [19].

The role of Opn in the process of granulomatous inflammation has been substantiated in numerous studies. O'Regan et al. have shown that Opn knock-out mice exhibit diminished formation of granulomas after artificial provocation with Schistosoma mansoni eggs in comparison to normal mice [18]. In agreement with these findings, it has been demonstrated that deficiency of osteopontin results in disseminated forms and worse prognosis of mycobacterial infections in human and murine hosts, indicating that a normal granulomatous response to mycobacterial agents is reduced by the deficiency of osteopontin [20,21].

The results of investigations in patients with sarcoidosis suggest that granulomatous lesions in sarcoidosis are characterised by a locally increased expression of OPN [5,13]. O'Reagan et al. demonstrated that the expression of OPN was localised to T-cell rich regions of sarcoid granulomas and that Opn could orchestrate early stages of granuloma formation [5]. Serum levels of Opn were also increased in certain stages of sarcoidosis in comparison with controls [13]. Opn predominantly stimulates Th1 arm of the T-cell immune response, which conforms to the notion of an increased 
Th1/Th2 ratio observed in sarcoidosis [22]. It is also of interest that Opn acts as a profibrogenic cytokine in addition to its proinflammatory properties, which may be related to the progression of sarcoidosis to the fibrotic form [23]. Several granulomatous diseases other than sarcoidosis, such as tuberculosis, silicosis and temporal arteritis are characterised by increases in OPN expression in contrast to other non-granulomatous inflammatory diseases $[3,5]$.

Genetic variation in the OPN gene was previously associated with susceptibility to diseases such as multiple sclerosis, systemic lupus erythematosus, carotid artery disease, nephrolithiasis, pseudoxanthoma elasticum and several others [8,24-28]. A possible association of variation in the OPN gene with sarcoidosis in the Japanese population was investigated by Akahoshi et al., who studied a single $(2514 \mathrm{C} / \mathrm{T})$ polymorphism in the OPN gene but failed to demonstrate any significant association with sarcoidosis in their study sample [29].

Functional effects of promoter SNP variants in the OPN gene were demonstrated by Giacopelli et al., who showed that specific alleles of these SNPs substantially affected the OPN expression in luciferase reporter experiments. Polymorphic variants identified in the promoter region were found to be located in the transcriptional factor binding sites regions, possibly affecting transcriptional regulation of the OPN gene [6]. Other discovered SNPs were located in the exonic and intronic regions with potential effects on mRNA splicing processes [30]. Additionally, a 3'-UTR variation was found to affect the expression of OPN gene significantly, possibly by affecting the stability and translational activity of the transcribed mRNAs [8].

The process of polymorphism selection for our study involved a recognition of patterns of linkage disequilibrium in the OPN gene region. A significant linkage disequilibrium was demonstrated in the region of OPN gene in previous association studies, which is also in agreement with data we obtained from the HapMap project $[7,8]$. It has been proposed that genotyping only a few SNPs in this region is sufficient to ascertain an association of variations in this region $[7,8]$. According to HapMap data, roughly three blocks of polymorphisms in significant linkage-equilibrium are present in the OPN gene region. In our study, we selected one SNP from each of these blocks in order to account for the effects of variation on sarcoidosis susceptibility across the whole OPN gene region. Finally, three polymorphisms with minor allele frequencies larger than 0.05 and with their location within a HapMap-defined haplotype block, had been selected: one promoter poly- morphism (rs11730582, -443C/T), located in the binding site of yet an uncharacterised transcription factor, one polymorphism located in intron 3 (rs11728697) and one in the exon 6 region (rs4754).

Our results suggest that the TTT combination of SNPs from each block is significantly associated with sarcoidosis. When analysing single polymorphismdisease associations, two SNPs - rs4754 and rs11728697 showed a borderline association with sarcoidosis, but when investigated in the combination on a haplotype, solid evidence of a significant association was obtained. Haplotyping methods may have the advantage of providing greater sensitivity and power to detect an association with a certain polymorphic variant, since wider genomic regions are taken into account. This approach may detect a disease-causing variant not directly investigated by genotyping but in linkage disequilibrium with polymorphisms accounted for $[31,32]$. Therefore, until further higher resolution analyses of the OPN locus are not performed, it is not possible to conclude whether one of the SNPs, investigated in this study is directly causal or only linked to a causal polymorphic site. Also functional studies of SNPs in the coding and 5'-UTR region are required, in addition to those performed by Giacopelli et al. in the OPN gene promoter region [6].

\section{Conclusion}

Our results suggest that variation in OPN gene in significantly associated with sarcoidosis and that TTT haplotype in the osteopontin gene may act as a protective factor in sarcoidosis. Further higher resolution studies are warranted to elaborate the precise etiologic variants conferring protection from sarcoidosis in the specific gene region.

\section{Acknowledgement}

This work was supported by Slovenian Research Agency grant P3-0326.

\section{References}

[1] G.W. Hunninghake, U. Costabel, M. Ando, R. Baughman, J.F. Cordier, R. du Bois, A. Eklund, M. Kitaichi, J. Lynch, G. Rizzato, C. Rose, O. Selroos, G. Semenzato and O.P. Sharma, ATS/ERS/WASOG statement on sarcoidosis. American Thoracic Society/European Respiratory Society/World Association of Sarcoidosis and other Granulomatous Disorders, Sarcoidosis Vasc Diffuse Lung Dis 16 (1999), 149-173. 
[2] E.M. Gravallese, Osteopontin: a bridge between bone and the immune system, J Clin Invest 112 (2003), 147-149.

[3] I. Carlson, K. Tognazzi, E.J. Manseau, H.F. Dvorak and L.F. Brown, Osteopontin is strongly expressed by histiocytes in granulomas of diverse etiology, Lab Invest 77 (1997), 103108.

[4] M. Jansson, V. Panoutsakopoulou, J. Baker, L. Klein and H. Cantor, Cutting edge: Attenuated experimental autoimmune encephalomyelitis in eta-1/osteopontin-deficient mice, $J$ Immunol 168 (2002), 2096-2099.

[5] A.W. O'Regan, G.L. Chupp, J.A. Lowry, M. Goetschkes, N. Mulligan and J.S. Berman, Osteopontin is associated with $\mathrm{T}$ cells in sarcoid granulomas and has $\mathrm{T}$ cell adhesive and cytokine-like properties in vitro, J Immunol 162 (1999), 10241031.

[6] F. Giacopelli, R. Marciano, A. Pistorio, P. Catarsi, S. Canini, G. Karsenty and R. Ravazzolo, Polymorphisms in the osteopontin promoter affect its transcriptional activity, Physiol Genomics 20 (2004), 87-96.

[7] A. Mas, A. Martinez, V. de las Heras, M. Bartolome, E.G. de la Concha, R. Arroyo and E. Urcelay, The 795CT polymorphism in osteopontin gene is not associated with multiple sclerosis in a Spanish population, Mult Scler 13 (2007), 250-252.

[8] S. D'Alfonso, N. Barizzone, M. Giordano, A. Chiocchetti, C. Magnani, L. Castelli, M. Indelicato, F. Giacopelli, M. Marchini, R. Scorza, M.G. Danieli, M. Cappelli, S. Migliaresi, B. Bigliardo, M.G. Sabbadini, E. Baldissera, M. Galeazzi, G.D. Sebastiani, G. Minisola, R. Ravazzolo, U. Dianzani and P. Momigliano-Richiardi, Two single-nucleotide polymorphisms in the 5' and 3' ends of the osteopontin gene contribute to susceptibility to systemic lupus erythematosus, Arthritis Rheum 52 (2005), 539-547.

[9] D.J. Schaid, C.M. Rowland, D.E. Tines, R.M. Jacobson and G.A. Poland, Score tests for association between traits and haplotypes when linkage phase is ambiguous, Am J Hum Genet 70 (2002), 425-434.

[10] M. Stephens, N.J. Smith and P. Donnelly, A new statistical method for haplotype reconstruction from population data, $A m$ J Hum Genet 68 (2001), 978-989.

[11] J.C. Barrett, B. Fry, J. Maller and M.J. Daly, Haploview: analysis and visualization of LD and haplotype maps, Bioinformatics 21 (2005), 263-265.

[12] Y. Benjamini and Y. Hochberg, False discovery rate: a practical and powerful approach to multiple testing, $J$ R Stat Soc B 57 (1995), 289-300.

[13] K. Maeda, K. Takahashi, F. Takahashi, N. Tamura, M. Maeda, S. Kon, T. Uede and Y. Fukuchi, Distinct roles of osteopontin fragments in the development of the pulmonary involvement in sarcoidosis, Lung 179 (2001), 279-291.

[14] M. Mazzali, T. Kipari, V. Ophascharoensuk, J.A. Wesson, R. Johnson and J. Hughes, Osteopontin-a molecule for all seasons, QJM 95 (2002), 3-13.

[15] D.T. Denhardt and X. Guo, Osteopontin: a protein with diverse functions, FASEB J 7 (1993), 1475-1482.

[16] S. Ashkar, G.F. Weber, V. Panoutsakopoulou, M.E. Sanchirico, M. Jansson, S. Zawaideh, S.R. Rittling, D.T. Denhardt, M.J. Glimcher and H. Cantor, Eta-1 (osteopontin): an early component of type-1 (cell-mediated) immunity, Science $\mathbf{2 8 7}$ (2000), 860-864.

[17] E.R. O’Brien, M.R. Garvin, D.K. Stewart, T. Hinohara, J.B. Simpson, S.M. Schwartz and C.M. Giachelli, Osteopontin is synthesized by macrophage, smooth muscle, and endothelial cells in primary and restenotic human coronary atherosclerotic plaques, Arterioscler Thromb 14 (1994), 1648-1656.

[18] A.W. O'Regan, J.M. Hayden, S. Body, L. Liaw, N. Mulligan, M. Goetschkes and J.S. Berman, Abnormal pulmonary granuloma formation in osteopontin-deficient mice, Am J Respir Crit Care Med 164 (2001), 2243-2247.

[19] E.E. Rollo, D.L. Laskin and D.T. Denhardt, Osteopontin inhibits nitric oxide production and cytotoxicity by activated RAW264.7 macrophages, J Leukoc Biol 60 (1996), 397-404.

[20] G.J. Nau, G.L. Chupp, J.F. Emile, E. Jouanguy, J.S. Berman, J.L. Casanova and R.A. Young, Osteopontin expression correlates with clinical outcome in patients with mycobacterial infection, Am J Pathol 157 (2000), 37-42.

[21] G.J. Nau, L. Liaw, G.L. Chupp, J.S. Berman, B.L. Hogan and R.A. Young, Attenuated host resistance against Mycobacterium bovis BCG infection in mice lacking osteopontin, Infect Immun 67 (1999), 4223-4230.

[22] K.X. Wang and D.T. Denhardt, Osteopontin: role in immune regulation and stress responses, Cytokine Growth Factor Rev 19 (2008), 333-345.

[23] J.S. Berman, D. Serlin, X. Li, G. Whitley, J. Hayes, D.C. Rishikof, D.A. Ricupero, L. Liaw, M. Goetschkes and A.W. O'Regan, Altered bleomycin-induced lung fibrosis in osteopontin-deficient mice, Am J Physiol Lung Cell Mol Physiol 286 (2004), L1311-L1318.

[24] L. de las Fuentes, C.C. Gu, S.J. Mathews, J.L. Reagan, N.P. Ruthmann, A.D. Waggoner, C.F. Lai, D.A. Towler and V.G. Davila-Roman, Osteopontin promoter polymorphism is associated with increased carotid intima-media thickness, $J \mathrm{Am}$ Soc Echocardiogr 21 (2008), 954-960.

[25] S. Han, J.M. Guthridge, I.T. Harley, A.L. Sestak, X. KimHoward, K.M. Kaufman, B. Namjou, H. Deshmukh, G. Bruner, L.R. Espinoza, G.S. Gilkeson, J.B. Harley, J.A. James and S.K. Nath, Osteopontin and systemic lupus erythematosus association: a probable gene-gender interaction, PLOS ONE 3 (2008), e0001757.

[26] B. Gao, T. Yasui, Y. Itoh, Z. Li, A. Okada, K. Tozawa, Y. Hayashi and K. Kohri, Association of osteopontin gene haplotypes with nephrolithiasis, Kidney Int 72 (2007), 592-598.

[27] D. Hendig, M. Arndt, C. Szliska, K. Kleesiek and C. Gotting, SPP1 promoter polymorphisms: identification of the first modifier gene for pseudoxanthoma elasticum, Clin Chem $\mathbf{5 3}$ (2007), 829-836.

[28] S. Caillier, L.F. Barcellos, S.E. Baranzini, A. Swerdlin, R.R. Lincoln, L. Steinman, E. Martin, J.L. Haines, M. PericakVance, S.L. Hauser and J.R. Oksenberg, Osteopontin polymorphisms and disease course in multiple sclerosis, Genes Immun 4 (2003), 312-315.

[29] M. Akahoshi, M. Ishihara, N. Remus, K. Uno, K. Miyake, T. Hirota, K. Nakashima, A. Matsuda, M. Kanda, T. Enomoto, S. Ohno, H. Nakashima, J.L. Casanova, J.M. Hopkin, M. Tamari, X.Q. Mao and T. Shirakawa, Association between IFNA genotype and the risk of sarcoidosis, Hum Genet 114 (2004), 503-509.

[30] J. Hull, S. Campino, K. Rowlands, M.S. Chan, R.R. Copley, M.S. Taylor, K. Rockett, G. Elvidge, B. Keating, J. Knight and D. Kwiatkowski, Identification of common genetic variation that modulates alternative splicing, PLoS Genet 3 (2007), e99.

[31] M. Li, M. Boehnke and G.R. Abecasis, Joint modeling of linkage and association: identifying SNPs responsible for a linkage signal, Am J Hum Genet 76 (2005), 934-949.

[32] R.W. Morris and N.L. Kaplan, On the advantage of haplotype analysis in the presence of multiple disease susceptibility alleles, Genet Epidemiol 23 (2002), 221-233. 


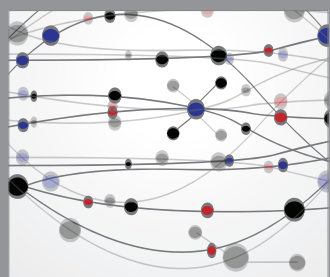

The Scientific World Journal
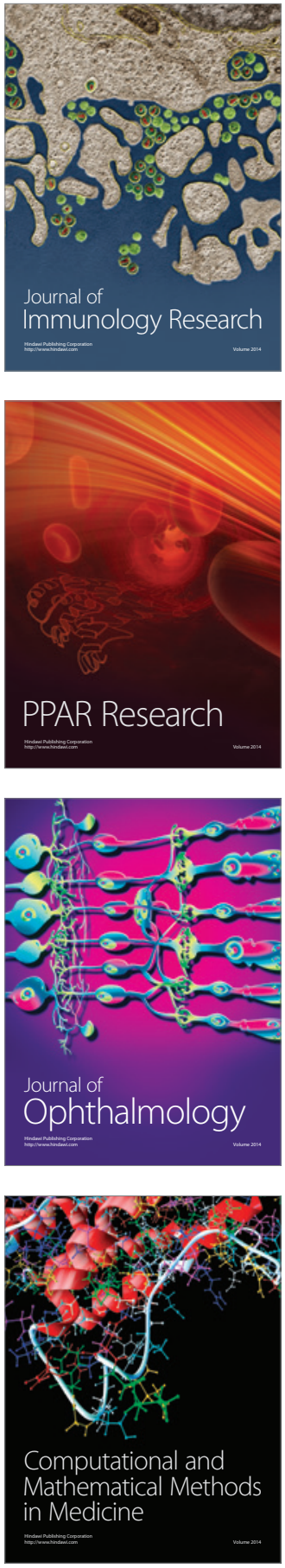

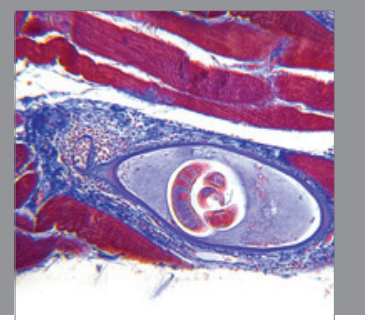

Gastroenterology

Research and Practice
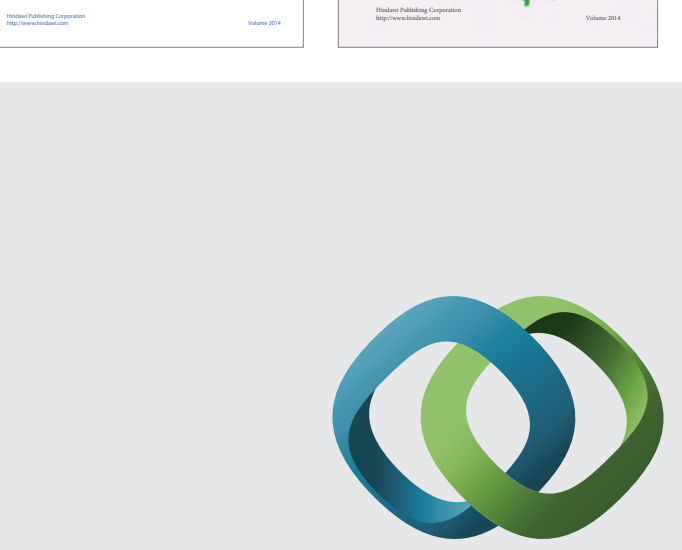

\section{Hindawi}

Submit your manuscripts at

http://www.hindawi.com
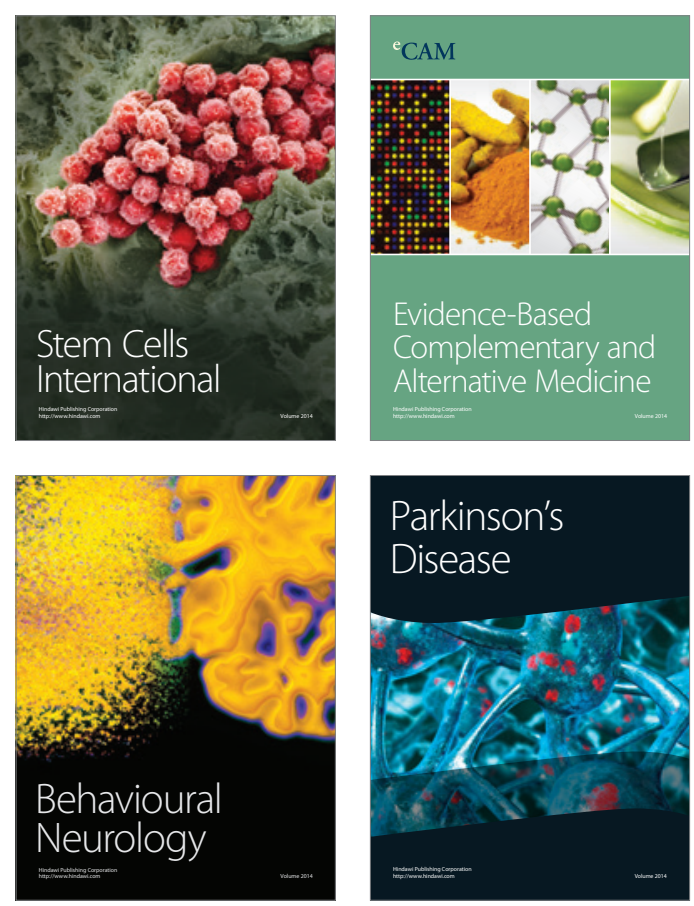

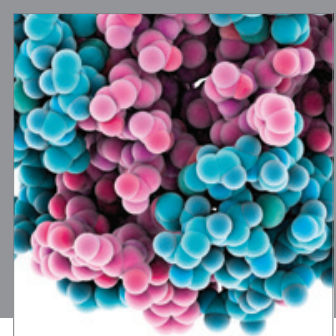

Journal of
Diabetes Research

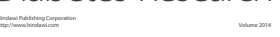

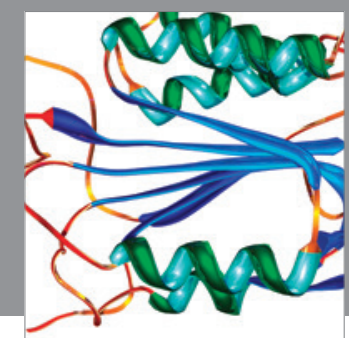

Disease Markers
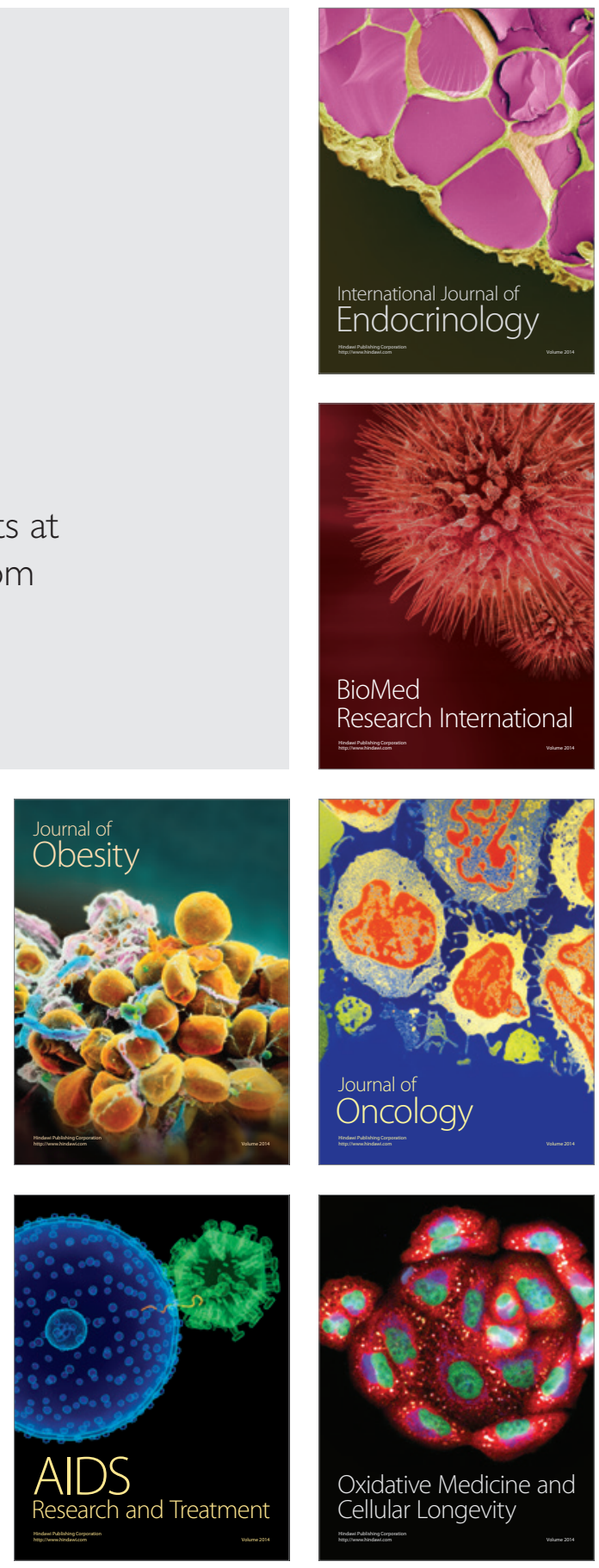